\title{
O estranho mapa do mundo baseado na produção científica está correto ou não estamos enxergando direito?
}

"Se o mundo fosse mapeado de acordo com quantos trabalhos de investigação científica cada país produz, assumiria uma aparência bizarra e irregular. $O$ norte se ampliaria, enquanto o hemisfério sul praticamente desapareceria". Essa foi a frase que estourou na rede mundial de computadores recentemente, indo parar até em redes sociais (http://hypescience.com/mapa-mundo-cienciaproducao-cientifica/), sobre um tal mapa mundial elaborado com base na produção acadêmico-científica dos países (Figura 1).

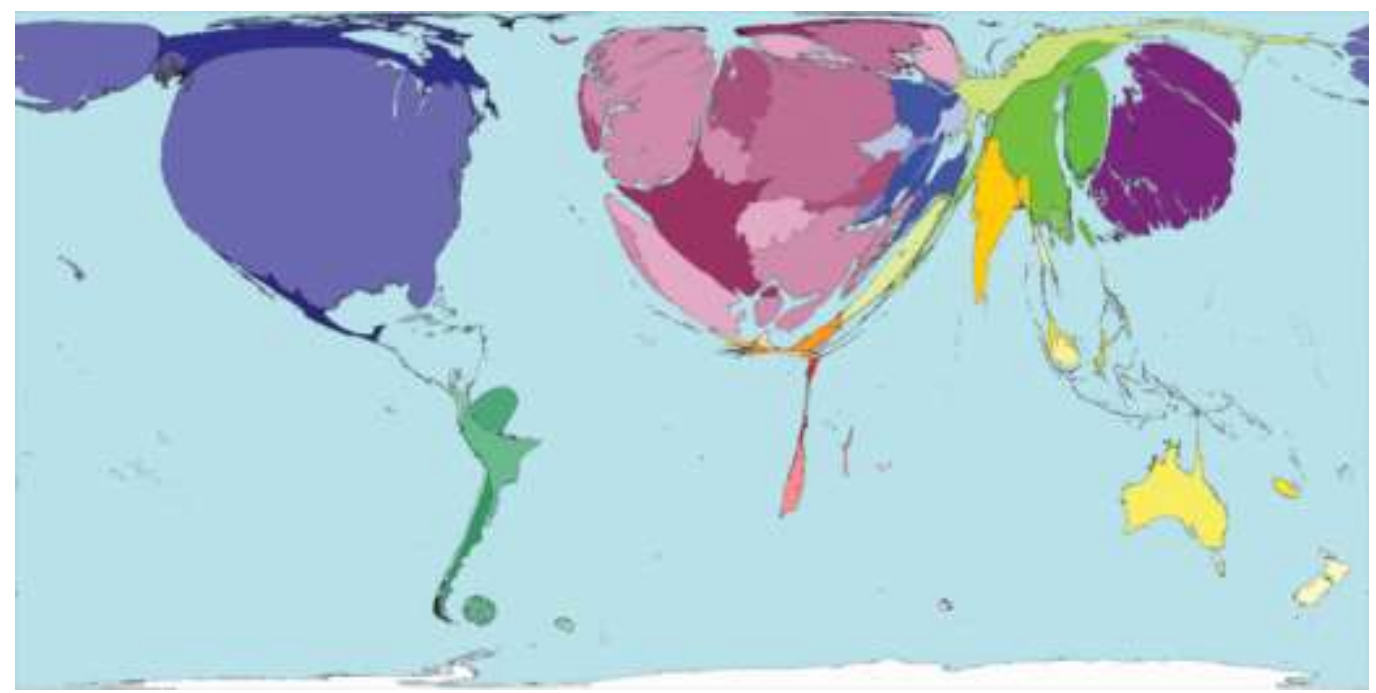

Figura 1. Estranho mapa do mundo baseado na produção científica. Disponível em: http://hypescience.com/mapa-mundo-cienciaproducao-cientifica/. Acesso em 18 abril de 2016.

O texto que acompanha o "estranho mapa", aponta para diferentes aspectos que explicam tamanha distorção na produção científica dos continentes. Dentre eles, destacam-se a falta de investimento dos países ("murchos") em pesquisa e inovação tecnológica, impulsionando os pesquisadores a gastar tempo ligando-se a organizações fora de suas universidades, uma vez que fundos nacionais não são disponibilizados como demandados; a tímida relação com o setor produtivo; e ausência de tecnologia em alguns continentes, como na África, onde a internet é mais lenta e mais cara em relação à regiões dos EUA, Europa e Ásia.

Outros aspectos indicados, talvez mais polêmicos, foram aqueles relacionados aos pesquisadores. 0 texto traz a informação de que "bons cientistas do hemisfério sul estão fazendo pesquisa no norte, longe de suas casas" e, por isso, não publicam em seus países. Por outro lado, "investigadores do norte que fazem pesquisa em países em desenvolvimento acabam publicando seus resultados nas mesmas revistas, localizadas no lado de cima do globo". E por fim, os autores do texto que acompanha o "estranho mapa" justificam que as distorções estão relacionadas à chamada "pesquisa invisível". Para os autores, o mapa "só conta como ciência artigos que são resultado da publicação em revistas científicas, ignorando coisas como monografias e relatórios técnicos e políticos, por exemplo. Além disso, exclui as ciências sociais e outros gêneros da área de humanidades". 
Algumas explicações interessantes, talvez devessem estar presentes no texto, evitando que leigos ou leitores curiosos façam julgamentos errôneos ou preconceituosos sobre as pesquisas que são desenvolvidas no hemisfério Sul.

A primeira diz respeito à contabilização da produção científica realizada. É obvio que os autores do mapa consideraram que a publicação de um artigo em uma revista dos EUA, por exemplo, contou para o referido país? Artigos publicados na Science, revista da "poderosa" American Association for the Advancement of Science (AAAS), certamente foram contados como publicação norte-americana? Ou levou-se em consideração os países de origem dos autores? Outro destaque é que uma porção expressiva da produção científica na America do Sul não foi publicada em períodicos de grandes indexadores, a exemplo, do Elsevier's, Scopus, Thomson Reuter's, Science Citation Index, etc. (Noorden 2014).

Nesse contexto, é preciso ponderar inúmeros fatores existentes nos países do hemifério Sul e que inexistem nos países do hemisfério Norte. No Brasil, particulamente, cita-se as fortes pressões impostas pelo conjunto de procedimentos utilizados pela Capes (Coordenação de Aperfeiçoamento de Pessoal de Nível Superior) para estratificação da qualidade da produção intelectual dos programas de pós-graduação, que têm forçado muitos pesquisadores brasileiros a publicarem suas melhores pesquisas em revistas com grandes indexadores sediadas nos EUA, Europa ou Ásia. Esse fato além de desvalorizar nossas revistas nacionais (que minguam por boas pesquisas) leva a subestimar a produção científica do país e permite que interpretamos de forma diferente o "estranho mapa", forçando-nos à acreditar que os países do hemisfério Sul produzem muito menos conhecimento do que os do hemisfério Norte.

Dizer que os países desenvolvidos possuem mais tecnologias e mais artifícios financeiros para fazerem pesquisas de ponta é coerente, mas é fato também que o mapa desconsidera alguns aspectos particulares da realidade e desenvolvimento da pesquisa na América do Sul. Muitas das pesquisas que estão "inchando" os países do hemisfério Norte são produzidas no Sul ou, se não, são os países do Sul produtores de boa parte do conhecimento publicado no hemisfério Norte. Outra importante ressalva é a produção a partir de colaborações internacionais: a quem é dado a propriedade? Nesse sentido, cabe uma leitura atenta do trabalho de Noorden (2014), publicado também na poderosa Nature, que reforça nossos argumentos.

No Brasil, parte da culpa disso, pode ser do nivelamento que a Capes quer fazer, a qualquer custo, com os números da produção científica brasileira. Rocha-e-Silva (2009) já questionava se o novo Qualis não seria uma tragédia anunciada. A conclusão do autor parece-nos excelente e oportuna neste momento para ser relembrada:

“Em conclusão, parece-me que algumas das premissas precisam ser repensadas. Os níveis propostos parecem altos demais. Parece que os autores resolveram aplicar um metro tipo Harvard ao Sistema brasileiro sem se darem conta que ainda temos que crescer um bocado antes de encarar Harvard de igual para igual. A regra dos 25\% parece provir de um ilusório "wishful thinking": mas não adianta desejar ardentemente que a distribuição de freqüência de conceitos seja normal, porque a heterogênea verdade brasileira garante que essa distribuição será qualquer coisa, menos normal. Finalmente, um pouco de patriotismo sadio nunca fez mal a ninguém (perguntem aos americanos!): algum suporte aos periódicos brasileiros é imperativo. Não estou sugerindo que se escancare a porteira: apenas que se dê aos periódicos brasileiros metas atingíveis de ambição de progresso".

Ao dispensarmos qualquer comentário ao autor, cabe apenas complementar que distorções grosseiras são inevitáveis quando construídas comparações a partir de cenários de realidades discrepantes. Neste contexto, podemos obter um similar e bizarro mapa de produção de conhecimento ao comparar apenas os países da América do Sul.. De qualquer forma, estejamos certos de que o mapa nos instiga a refletir sobre a emergente necessidade de encararmos a pesquisa como algo mais sério (e menos amador e produtivista) e valorizarmos mais nossos periódicos nacionais, para que nossas melhores pesquisas não causem uma intepretação enviesada, levando-nos à crer que os países do hemifério Sul pouco ou nada contribuem para construção científica mundial.

Desejamos a todos uma ótima leitura dos artigos publicanos nesta nova edição da Multi-Science Journal.

Prof. Dr. Guilherme Malafaia

(Editor Chefe)

Instituto Federal Goiano - Campus Urutaí e-mail: guilhermeifgoiano@gmail.com

Prof. Dr. Ivandilson Pessoa Pinto de Menezes (Editor da área de Ciências Biológicas)

Instituto Federal Goiano - Campus Urutaí e-mail: ivan.menezes@ifgoiano.edu.br

\section{Referências}

Noorden RV. South America - by the numbers. Nature. 510: 1-2, 2014

Rocha-e-Silva M. 0 novo Qualis, ou a tragédia anunciada. Clinics, 64(1) :1-4, 2009. 